\title{
EXPERIENCE OF THE RUSSIAN FEDERATION ON DEVELOPMENT OF METHODS FOR N-NITROSOAMINES CONTROL IN FOOD (CHILDREN'S CANNED MEAT PRODUCTS)
}

\author{
N.V. Zaitseva, T. S. Ulanova, T. V. Nurislamova, D. V. Suvorov \\ FBSI "Federal Scientific Center for Medical and Preventive Health Risk Management \\ Technologies", house 82, Monastyrskaya street, Perm, 614045, Russia
}

(Ngày đến tòa soạn: 15/6/2018; Ngày sủa bài sau phản biện: 18/7/2018; Ngày chấp nhận đăng: 27/7/2018)

7 his paper deals with the methodical techniques used in the practice of development and appli1 cation of methods for determining chemical compounds in food. The gas chromatography mass spectrometric method for determining highly toxic, carcinogenic $N$-nitrosoamines (N-nitrosodimethylamine, $N$-nitrosomethylethylamine, $N$-nitrosodiethylamine, $N$-nitrosopyrrolidine, $N$-nitrosomorpholine, N-nitrosodibutylamine, $\quad N$-nitrosodipropylamine, $\quad N$-nitrosopiperidine and $N$-nitrosodiphenylamine) $N$-nitrosodiphenylamine in food products was proposed. High sensitivity and selectivity of chromatography-mass spectrometric identification of $N$-nitrosoamines in food samples with the lower limit of determination of $0.0002 \mathrm{mg} / \mathrm{kg}$ and a maximum error of not more than 23\% were achieved under the optimal conditions for chromatographic analysis: a capillary column HP - FFAP $50 \mathrm{~m} * 0.32 \mathrm{~mm}$ i.d. $* 0.50 \mathrm{~m}$; temperature mode of column programming: initial temperature of $50^{\circ} \mathrm{C}$, increasing the temperature up to $120^{\circ} \mathrm{C}$ at the speed of $8^{\circ} \mathrm{C} / \mathrm{min}$; from $120^{\circ} \mathrm{C}$ to $185^{\circ} \mathrm{C}$ at the speed of $12^{\circ} \mathrm{C} / \mathrm{min}$, and from $185^{\circ} \mathrm{C}$ to $240^{\circ} \mathrm{C}$ at the speed of $25^{\circ} \mathrm{C} / \mathrm{min}$ with a holding at the final temperature for $5 \mathrm{~min}$; operation mode of mass spectrometer: selective ion monitoring (SIM) of two characteristic ions of analyzed compounds $\mathrm{m} / \mathrm{z}$. Comprehensive use of $\mathrm{N}$-nitrosoamines distillation with the salting-out agent when combined with the optimal scheme elution of solid-phase extraction and concentration of the distillate on carbon cartridge Coconut $6 \mathrm{~mL}$ enabled to achieve full $N$-nitrosoamines extraction from food samples (93.2-100\%). Nine N-nitrosoamines in the concentration range of $0.030 \pm 0,011 \div 3.89 \pm 0.83 \mathrm{mg} / \mathrm{kg}$ were found in food samples $(n=16)$.

Keywords: Nitrosamines, canned meat, food, gas chromatography, mass spectrometry

\section{Introduction}

Ensuring the protection of human health from exposure to hazardous and harmful factors related to food in the Russian Federation is becoming increasingly relevant [1]. Food products and their components must comply with hygienic safety requirements of the technical regulations [2]. However, the potentially hazardous compounds are designated in the technical regulations not in all food, and a number of existing requirements to these compounds needs to be clarified. Thus, a group of highly toxic, carcinogenic N-nitrosoamines including N-NDMA (N-DMNA), N-nitrosomethylethylamine (N-MENA), N-nitrosodiethylamine (N-DENA), N-nitrosopyrrolidine (N-DPNA), N-nitrosodi-n-Propylamine (N-DBNA), N-nitrosopiperidine (N-PIPNA), N-nitrosodi-n-butylamine (N-PYRNA), N-nitrosomorpholine (N-MORNA), N-nitrosodiphenylamine (N-DPHNA) might cause high risk.

The compounds levels in the EAEU for a number of products are allowed at the level of 0.002$0.004 \mathrm{mg} / \mathrm{kg}$. Nevertheless, the N-nitrosoamines level is not allowed in children food products, 
canned meat and fish, as well as semi-finished products from fish [2, 3]. In the European Union there were no data about specified standard of N-nitrosoamines level in food products, including meat and fish products [12].

According to several former studies (Italy, Denmark, China) N-nitrosamines were found in meat products at the range of 0.051-9.4 mg/kg [4, 5]. However, when food was examined in Russia with mass spectrometry, it turned out to contain purposeless N-nitrosoamines level unstated by manufacturers in food products, including products for young children.

However, quantitative assessment of its level and safety for health is challenging because of the lack of highly sensitive, highly selective, reproducible and reliable methods for determining these toxic compounds.

In this regard, the task to develop a quantitative determination of $\mathrm{N}$-nitrosoamines level in food products to evaluate their safety is quite relevant.

For the quantitative determination of contaminants in food it is appropriate to use combination of gas chromatography and mass spectrometry (GC/MS) methods [6]. An important step is the extraction and collection of analyzed compounds from a complex matrix of studied sample. Currently, a promising method for sample preparation for chemical analysis is solid phase extraction (SPE) [7].

Keywords: N-nitrosamines, solid-phase extraction (SPE) cartridge (carbon Coconut), chromatography-mass spectrometry, quadrupole mass spectrometric detector.

\section{Materials and methods}

Development and certification of chromato-mass-spectrometric techniques to analyze the N-nitrosoamines in food (smoked meat, meat- and poultry - products) was carried out according to GOST R 8.563-2009 [8]. Metrological certification of the techniques was performed in accordance with the regulations of RMG 61-2010 [9].

Meat products were collected from the market via random sampling technique.

The subjects of the study were: optimizing chromatographic conditions and mass spectrometric analysis; chromatographic behavior of analyzed compounds on different stationary liquid phases; the metrological characteristics of the measurement process, the experimental test conditions and parameters of samples preparation in food for chemical analysis.

Gas chromatograph Agilent 7890A (USA) with quadrupole mass spectrometric detector (MCD) 5975C was used. Ionization mode was with electron impact at $70 \mathrm{eV}$. Solvents including dichloromethane (HPLC) (PanReacAppliChem) of 99.9\%; acetonitrile (HPLC) (PanReacAppliChem) of 99.9\%; 2-propanol multisolvent (HPLC) (Scharlau) of 99.99\%; ethyl acetate, multisolvent (HPLC) (Scharlau) of $99.97 \%$ were used for automatic system of solid phase extraction functioning.

Coal Cartridge Coconut Charcoal SPE (30 pk 2g/6 ml) (Supelco, Pennsylvania, USA) was also applied.

For quantitative determination of $9 \mathrm{~N}$-nitrosoamines a standard solution was used $\left(0.16 \mathrm{mg} / \mathrm{cm}^{3}\right)$; it was EPA 521 Nitrosamine Mix, consisting of N-DMNA, N-MENA, N-DENA, N-DPNA, NDBNA, N-PIPNA, N-PYRNA, N-MORNA, N-DPHNA. Using standard solutions and basing on measurement results the calibration curve was built using the method of chromato-mass-spectrometry in the mode of selective ion monitoring (SIM) on characteristic ions of compounds 74, 88, 102, 130, $84,114,100,116,168 \mathrm{~m} / \mathrm{z}$ at concentrations of 0.0002-0.0016 inch mg/kg 0.016-5.0 mg/kg. Methylene chloride, hexane (chemically pure TU 2631-158-44493179-13), potassium hydroxide (GOST 24363-80), methyl alcohol $\mathrm{CH}_{3} \mathrm{OH}$ were used.

The precision of this method was estimated via adding analytes at three concentrations of 0.0002 $(0.016), 0.0008(0.008)$ and $0.0016(0.0008) \mathrm{mg} / \mathrm{kg}$. The indicator of intra-laboratory precision of 
$4.84 \%$, the accuracy index being no more than $10 \%$ and the accuracy rate equal to $19 \%$ were achieved [9].

The method for preparing food samples were aimed at selecting a brand of a cartridge (carbon Coconut $6 \mathrm{~mL}$ octadecyl filled with Chromabond C18, 100 and $500 \mathrm{mg}$ cartridges, polymerbased Strata $200 \mathrm{mg}$ ), and then the SPE elution schemes and distillation at standard samples were worked out.

\section{Results and discussions}

Application of capillary columns with different characteristics of stationary liquid phases: DB$624-25 \mathrm{~m}_{*} 0.32 \mathrm{~mm} * 5.0 \mu \mathrm{m}$; HP-FFAP- $50 \mathrm{~m} * 0.32 \mathrm{~mm} * 0.5 \mu$ ти, HP- $1-35 \mathrm{~m}_{*} 0.32 \mathrm{~mm} * 0.25 \mu \mathrm{m}$ was investigated. High performance of the chromatographic separation of N-nitrosoamines with different physic-chemical properties was achieved on capillary column series HP- FFAP $50 \mathrm{~m}_{*} 0,320$ $\mathrm{mm}_{*} 0,50 \mu \mathrm{m}$. Column programming mode involved: initial temperature $50^{\circ} \mathrm{C}$, temperature increasing up to $120^{\circ} \mathrm{C}$ with speed rate $8^{\circ} \mathrm{C} / \mathrm{min}$; from $120^{\circ} \mathrm{C}$ up to $185^{\circ} \mathrm{C}$ with speed rate $12^{\circ} \mathrm{C} / \mathrm{min}$ and from $185^{\circ} \mathrm{C}$ up to $240^{\circ} \mathrm{C}$ with speed rate $25^{\circ} \mathrm{C} / \mathrm{min}$ at finite-temperature exposures lasting for 5 minutes. Helium was used as a gas carrier; gas carrier speed was $1.0 \mathrm{ml} / \mathrm{min}$ in constant flow mode. Analytical temperature interface was $220^{\circ} \mathrm{C}$. Sample entry was performed with the use of automatic injector Agilent ALS in the mode pulsed/splitless; sample volume was $2 \mathrm{mql}$.

The working mode of mass-spectrometric detector (for the quantitative analysis in the range of concentrations $0.0002-5.0 \mathrm{mg} / \mathrm{kg}$ ) was selective ion monitoring (SIM) according to three characteristic ions of analyzed compounds. Chromato-mass-spectrometric parameters for N-nitrosoamines determination in food samples (children's canned meat) were: split ratio helium:air, flow mode was $30 \mathrm{ml} / \mathrm{min}$.

When both optimal solid-phase extraction and chromato-mass-spectrometric analysis conditions were achieved, it allowed to get high efficiency of N-nitrosoamines' separation of the standard sample (Fig.1)

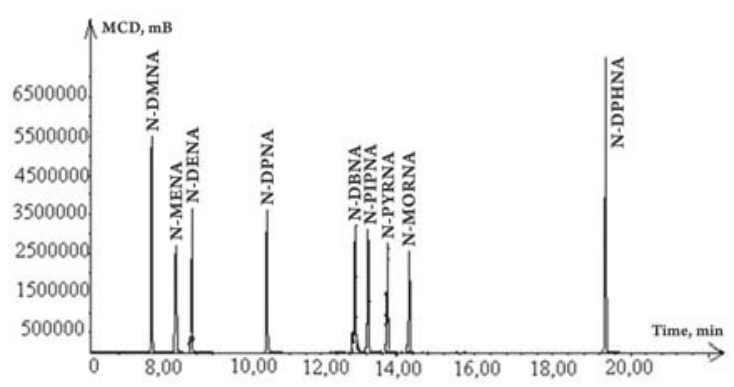

Fig. 1. Chromatogram of $N$ - nitrosoamines of the standard solution registered on total ion current (TIC): 1-N-dimethylnitrosamine (DMNA); 2- $\mathrm{N}$ - methyl ethylnitrosamine; 3- $\mathrm{N}$ diethylnitrosamine; 4-N-pyrrolidinitrosamine; 5-N-morpholinnitrosamine; 6- $N$-dibutylnitrosamine; 7- $N$-dipropylnitrosamine; 8- $N$-piperidinitrosamine; 9- $N$-nitrosodiphenylamine.

To suppress the matrix effects of food products to increase the selectivity and completeness of their extraction, interfering components and fat in food samples were removed by adding salting-out reagents, followed by distillation with superheated steam and concentrating the distillate on cartridges of the automatic solid-phase extraction (SPE) system (Sepaths) [10]. To execute the distillation process of N- nitrosoamines from the food productthe amount of 20-50 g sample weight was placed in a distillation flask with a volume of $500 \mathrm{~cm}^{3}$ coupled with a steam generator and a direct condenser. The salting-outreagents ( $5 \mathrm{~g}$ of sodium sulfate and $5 \mathrm{~g}$ of sodium chloride) were added into a food product, $50-100 \mathrm{~cm}^{3}$ of distilled water, $2.5 \mathrm{~cm}^{3}$ of $2 \%$ sulfamic and $0.5 \mathrm{~cm}^{3}$ of $60 \%$ sulfuric acid solution up to $\mathrm{pH}=3$ and $\mathrm{N}$-nitrosoamines were distilled with superheated steam $\left(\mathrm{t}_{\text {steam generator }}=(100 \pm 5)^{\circ} \mathrm{C}\right.$ 
and $\left.\mathrm{t}_{\text {flask with food sample }}=(80 \pm 5)^{\circ} \mathrm{C}\right)$, collecting $70 \mathrm{~cm}^{3}$ of distillate. After that the distillate was passed through a carbon cartridge of an automatic SPE system with application of a selective elution scheme. The elution scheme included 4 stages. The activation stage of the cartridge was performed with $2 \mathrm{~mL}$ of methylene chloride, then with $2.0 \mathrm{~mL}$ of ethyl acetate with a solvent retention for 30 sec. To remove residual amounts of solvents, the cartridge was rinsed with $2 \mathrm{~mL}$ of water and the automatic system was purged with nitrogen within 2 minutes. The adsorption stage of the target components on the cartridge included loading of the sample with a volume of $70 \mathrm{~mL}$. To remove residual amounts of the sample, the cartridge was dried for 20 minutes and the system was purged with nitrogen within 2 minutes. The final stage was elution of the target analytes from the cartridge with $4 \mathrm{~mL}$ methylene chloride and purging the automatic system with nitrogen within 2 minutes. Then, an extract of methylene chloride in the volume of $2 \mathrm{~mm}^{2}$ was injected through an evaporator into a chromatography column of a chromatograph.

The study results on the completeness of N-nitrosoamines extraction from food products using a standard sample by distillation and SPE on carbon cartridge Coconut $6 \mathrm{~cm}^{3}$ were shown in Table 1.

Table 1. The results on the completeness of the extraction of $N$-nitrosoamines

\begin{tabular}{|l|c|c|c|}
\hline \multicolumn{1}{|c|}{ Component } & Entered, $n$ g & Detected, $n$ & $\begin{array}{c}\text { Completeness of } \\
\text { the extraction, } \\
\text { \% }\end{array}$ \\
\hline 1. N-dimethylnitrosamine & 160 & 157.0 & 98.13 \\
\hline 2. N- methylethylnitrosamine & 160 & 159.0 & 99.9 \\
\hline 3. N-diethylnitrosamine & 160 & 159.0 & 99.85 \\
\hline 4. N-dipropylnitrosamine & 160 & 158.5 & 99.8 \\
\hline 5. N-dibutylnitrosamine & 160 & 158.1 & 98.8 \\
\hline 6. N-piperidinitrosamine & 160 & 158.0 & 98.75 \\
\hline 7. N-pyrrolidinitrosamine & 160 & 75.7 & 93.2 \\
\hline 8. N-morpholinnitrosamine & 160 & 112.8 & 94.0 \\
\hline 9. N-nitrosodiphenylamine & 160 & 65.1 & 93.2 \\
\hline
\end{tabular}

The use of $\mathrm{N}$-nitrosamines distillation with the addition of salting-out reagents in combination with the optimal elution scheme for solid-phase extraction and concentration of the distillate on a Coconut carbon cartridge of $6 \mathrm{~mL}$ made it possible to achieve complete recovery of $\mathrm{N}$-nitrosamines from food samples $93.2-100 \%$. When the developed chromatography-mass spectrometric method was tested, the screening studies of food products for child nutrition, produced by various manufacturers, were executed in the mode of selective ion monitoring (SIM).

In the food product samples $(n=16) 9 \mathrm{~N}$-nitrosamines was detectedin concentration range of $0.030 \pm 0.011 \div 3.89 \pm 0.83$ (Fig.2). In accordance with the technical regulations of the Customs Union the presence of N-nitrosamines in children's food products is not allowed [2].

Thus, the proposed methodology allows to perform the quantification of the detected N-nitrosoamines in food products, including those that occur casually and are undeclared.

The availability of this method technique is considered to be a precondition for improving the 


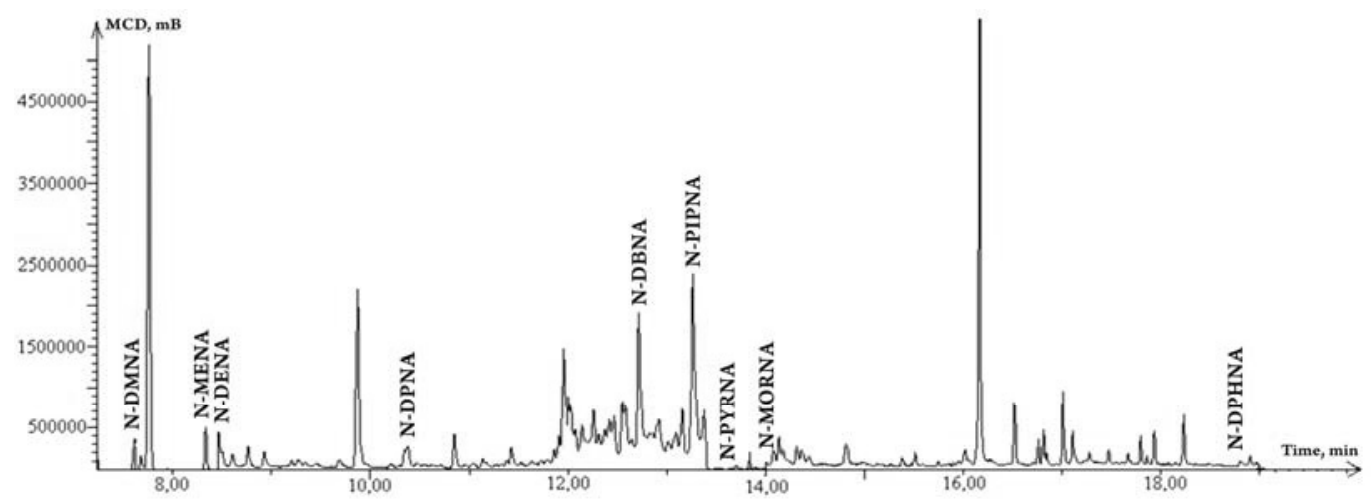

Fig.2. Chromatogram of $N$-nitrosoamines detected in a sample of child food product: $C N-D M N A=0.0012 \mathrm{mg} / \mathrm{kg}, C N-M E N A=n / d$ (not detected), $C N-D E N A=n / d, C N-$ $D P N A=0.0045 \mathrm{mg} / \mathrm{kg}, C N-D B N A=0.015 \mathrm{mg} / \mathrm{kg}, C N-P I P N A=n / d, C N-P Y R N A=n / d$, $C N-M O R N A=0.038 \mathrm{mg} / \mathrm{kg}, C N-D P H N A=0.0033 \mathrm{mg} / \mathrm{kg}$

requirements of the Technical Regulation of the Customs Union "On Food Safety" to the content of $\mathrm{N}$-nitrosamines in food products and to ensure its safety for human health.

\section{REFERENCE LIST}

1. The draft strategy of state policy to ensure the quality and safety of food products till 2020.

2. About food safety: Technical regulations of the Customs Union TR CU 021/2011 dated $9^{\text {th }}$ of December 2011 No. 880.

3. Technical regulations of the Eurasian Economic Union "On safety of fish and fish products" (TR EAEU 040/2016).

4. Yuan Y., Meng W., Yutian M., Fang C., Xiaosong H. Determination of Eight Volatile Nitrosamines in Meat Products by Ultrasonic Solvent Extraction and Gas ChromatographyMass Spectrometry Method. International Journal of Food Properties, 2015;18:1181-1190.

5. S Herrmann.S., Duedahl-Olesen L., Granby K. Simultaneous determination of volatile and non-volatile nitrosamines in processed meat products by liquid chromatography tandem mass spectrometry using atmospheric pressure chemical ionisation and electrospray ionization. Journal of Chromatography A, 2014; (1330): 20-29.

6. Malysheva A. G., Rakhmanin Yu. A. Physico-chemical studies and methods for control substances in environmental health. St. Petersburg Scientific Production Association "Professional", 2012: 720.

7. Zaitsev V. N., Zui M. F. Microextraction solid-phase concentration. - Journal of analytical chemistry, vol 69, No. 8, 2014. - p.1-14.

8. GOST R 8.563-2009 State system for ensuring measurement unity. Measurement methods. URL: www.tsu.ru/upload/medialibrary/2c9/gost $r$ 8563 2009.pdf(accessed 23 February 2017)

9. RMG 61-2010. State system for ensuring the measurement unity. Precision, accuracy and trueness index of methods for quantitative chemical analysis. Assessment methods. URL: http://docs.cntd.ru/document/1200094703 (accessed 20 June 2017).

10. Standard of organization STO M 24-2016 Measurement method for N-nitrosamines level (N-diethylnitrosamine, N-methylethylenediamine, N-diethylnitrosamine, N-dipropylenetriamine, N-dibutylnitrosamine, N-piperidinylmethyl) in food products (canned meat, meat and cereal) using chromato-mass-spectrometry. 